\title{
Open field and a behavior score in PNT model for neuropathic pain in pigs
}

\section{David Castel' \\ Itai Sabbag ${ }^{2}$ \\ Elvira Nasaev ${ }^{3}$ \\ Sean Peng ${ }^{4}$ \\ Sigal Meilin ${ }^{3}$}

'The Neufeld Cardiac Research Institute, Sheba Medical Centre, Sackler School of Medicine, Tel Aviv University, Tel Aviv, Israel; ' 2 Lahav Research Institute, Kibutz Lahav, Negev, Israel; ${ }^{3}$ Neurology R\&D Division, MD Biosciences, Ness Ziona, Israel; ${ }^{4}$ Touchstone Biosciences, Plymouth Meeting, PA, USA
Correspondence: Sigal Meilin Neurology R\&D Division, MD Biosciences, 3 Sapir str., Ness Ziona $74 \mid 40$, Israel

$\mathrm{Tel}+97289396884$

Fax +972 89396885

Email sigal@mdbiosciences.com
This article was published in the following Dove Press journal: Journal of Pain Research

Background: Rodent models are frequently used in the research of pain and continue to provide valuable data on the mechanisms driving pain, although they are criticized due to limited translational ability to human conditions. Previously we have suggested pigs as a model for development of drugs for neuropathic pain. In this study, we investigate the spontaneous behavior of pigs following peripheral neuritis trauma (PNT)-induced neuropathic pain.

Methods: A computerized monitoring system was used to evaluate the changes in open field test in addition to applying a composite behavior scoring system. The data suggest that the PNT operation did not affect the animal's ability to walk as the total distance walked by PNT animals was not significantly different from the total distance walked by sham-operated animals. However, PNT animals expressed a significant change in the pattern of walking. This effect was unrelated to the time that the animals spent in the open field. Following treatment with different drugs (morphine, buprenorphine, or gabapentin), the walking pattern of the animals in the open field changed in a drug-specific manner. In addition, the detailed behavior score revealed drug-specific changes following treatment.

Results: Pharmacokinetic analysis of the drug concentration in blood and cerebrospinal fluid correlated with the behavioral analysis.

Conclusion: The data of this study suggest that the open field test together with the detailed behavior score applied in this model are a powerful tool to assess the spontaneous behavior of pigs following PNT-induced neuropathic pain.

Keywords: open field, swine, neuropathic pain

\section{Introduction}

Animal models of pain are important for understanding the pain process and have been developed to understand pain from a variety of disease states. Animal models of pain include two components: the method of insult and the subsequent end-point measurement. Rodent models are frequently used, and these include a variety of methods for assessing changes in rodents' spontaneous behavior following chronic pain, such as fecal scoring, ${ }^{1}$ voluntary movement rearing, ${ }^{2}$ and others. However, even though rodent models for pain continue to provide valuable data on the mechanisms driving pain, ${ }^{3,4}$ the use of these models in drug development is criticized due to limited translational ability to human conditions..$^{5-10}$

Pigs are increasingly being used in regulatory toxicology studies ${ }^{10}$ as they share similar anatomic and physiologic characteristics with humans in a number of organ systems ${ }^{11}$ and may be an alternative to NHPs for bridging the gap in behavioral studies 
between rodent preclinical research and human clinical trials. ${ }^{12}$ However, very little is known about the spontaneous behavior changes in pigs following painful procedures. In a previous work, Castel at al showed that in accordance with other species, pigs express stimuli-related withdrawal activity in a PNT model and that the pig model more closely resembles humans than other models. In their work, the authors suggest a behavior scoring system for assessing animal behavior following PNT. ${ }^{5}$ In the current study, we aimed to further characterize the non-evoked behavior of pigs exposed to PNT and treated with different therapies using the open field test.

The open field test has been used widely in rodents to assess locomotor function, anxiety, and stress. ${ }^{13,14}$ However, the use of this method in pigs is very limited and rarely involves computerized objective observations. The open field assay was used previously to assess the effect of CNS drugs such as cocaine on young and mature pigs. ${ }^{15}$ More recently, Zhong et $\mathrm{al}^{16}$ studied the potential use of the open field in assessing neurotoxicity in Sinclair minipigs. They looked at the effect of amphetamine, ketamine, and diazepam on pigs' behavior in the open field and concluded that the open field is useful for functional observation of behavior in pigs. However, their method of analysis involved subjective observations and scoring. Others have used locomotor activity observations to evaluate the effect of injection methods to the sciatic nerve area. ${ }^{17}$ All these studies were conducted using different methods of scoring while subjectively observing animal behavior in the open field, and none were performed on pigs with neuropathic pain. To the best of our knowledge, our study is the first time that the behavior of pigs under neuropathic conditions has been studied using a computerized online monitoring system for the open field method.

\section{Methods}

\section{Animals and housing}

Danish Landrace $\times$ Large White crossbred pigs from the domestic herd at Lahav Labs, Negev, Israel, were used in this study. All procedures and experiments were approved by the MD Biosciences Animal Care and Use Committee (IACUC) and the Israel National Animal Care and Use Committee and were designed to reduce numbers and undue suffering in accordance with IASP (International Association for the Study of Pain).$^{18}$ Prior to the start of the study, all of the animals were kept under conventional pig production conditions. Animals were housed in open pens $(1.4 \times 2.4 \mathrm{~m})$ on a 12 hours: 12 hours light-dark cycle for 7 days prior to study initiation. Feeding occurred three times daily using specific food for pigs (Dry Sows; Ct \# 5420; Milobar, 7880, Oshrat, Israel), and pigs were provided opportunities to root and chew for enrichment. Fresh water was provided ad libitum by an automated system.

\section{Study design}

Thirty-six animals were included in this study, with six animals assigned to each treatment group. It is important to note that the variability in this study is relatively low. Therefore, the number of animals required to achieve statistical difference is significantly lower than in behavior rodents studies. Sham-operated animals underwent anesthesia and sciatic nerve exposure maintaining the sciatic nerve intact. Table 1 shows the study design. Animals from group three were dosed with $1 \mathrm{mg} / \mathrm{kg}$ morphine 3 weeks post-surgery; following 3 days washout the animals were then dosed with $2 \mathrm{mg} / \mathrm{kg}$ morphine. Following 4 days washout, the same animals were re-dosed with $5 \mathrm{mg} / \mathrm{kg}$ morphine. All doses were performed IM at the area of the neck. Animals from group four were dosed with buprenorphine at a dose of 0.5 $\mathrm{mg} / \mathrm{kg}$ IM. Animals from group five were dosed with $6 \mathrm{mg} /$ $\mathrm{kg}$ gabapentin using the IV route.

\section{Habituation}

Pigs were allowed to habituate to the study protocol for 5 days prior to surgery as described previously. ${ }^{6}$ To familiarize the pigs with the schedule and technicians, the same technician and group of researchers were involved for the duration of the study period. During the habituation period, these persons entered the animals' pen twice daily and played with the pigs for a period of 15 minutes. The habituation process was implemented to reduce the stress level of the pigs.

\section{Anesthesia and surgery}

Each pig walked freely to the preparation room on the day of surgery. A technician carried each animal in their hands and placed an anesthetic facemask (Fritz Stephan GmbH Medizintechnik, Gackenbach, Germany) on the pig's mouth and nose, as described previously. ${ }^{5}$ Each animal was anesthetized with a $3 \%$ isoflurane $/ 100 \%$ oxygen mixture. The pig was placed in the sternal position on the operating table. The area of the incision was swabbed with antiseptic liquid polidine solution (Polysept solution, Rekah Pharmaceutical Industry Ltd., Holon, Israel) and the non-operated areas were covered with sterile sheets. During anesthesia, blood $\mathrm{O}_{2}$ saturation was monitored (Spacelab Medical, Snoqualmie, WA, USA). The temperature in the surgery room was maintained at $19^{\circ} \mathrm{C}$ (range $18^{\circ} \mathrm{C}-20^{\circ} \mathrm{C}$ ). 


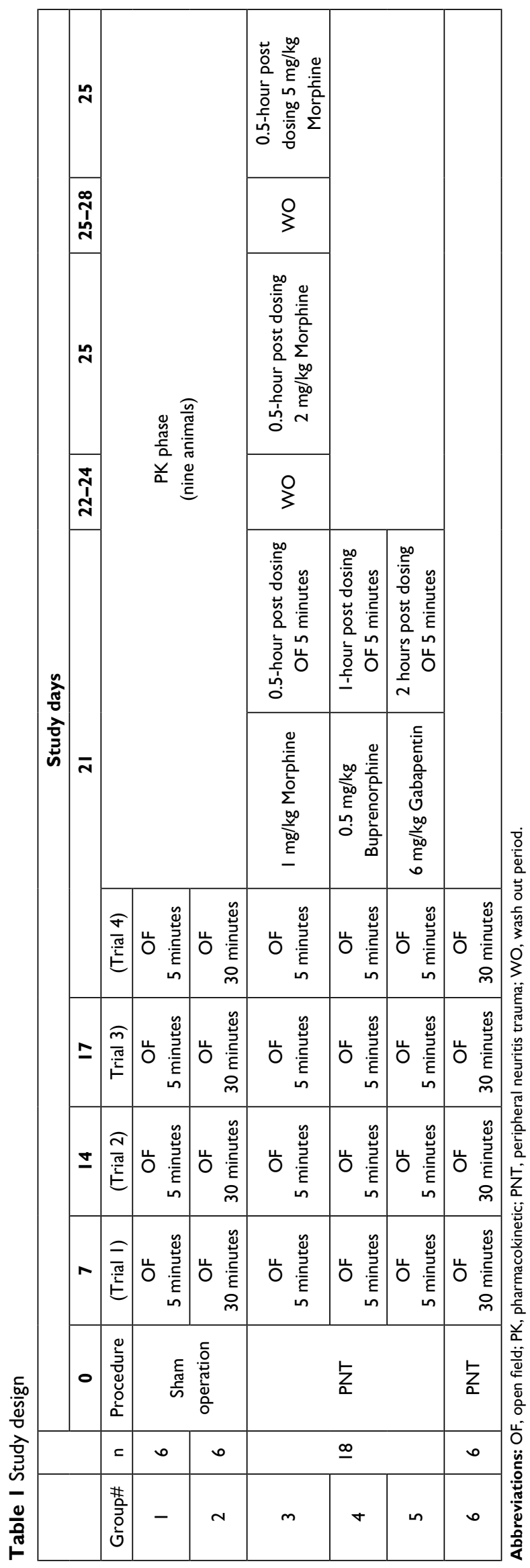

PNT was induced as previously described. ${ }^{5}$ Briefly, following a full skin incision of $8-10 \mathrm{~cm}$ on the left side of the lower back, the muscles were retracted exposing the entire sciatic nerve. PNT was induced by three 3-0 silk threads (Assut Medical Sàrl, Pully-Lausanne, Switzerland), each $3 \mathrm{~cm}$ in length, which were pre-soaked in CFA $(1 \mathrm{mg} / \mathrm{mL})$ overnight. These threads were ligated loosely (1-2 mm apart) surrounding the lateral half of the sciatic nerve bundle. Sham-operated animals underwent the same procedure of skin incision and sciatic nerve exposure, leaving the nerve intact.

\section{Open field test for locomotor activity}

The open field apparatus size was $2.5 \mathrm{~m}$ wide and $4.8 \mathrm{~m}$ long. The walls of the open-field were smooth and $1.6 \mathrm{~m}$ high. The animals were introduced to the open field for a period of 5 minutes or 30 minutes. The walking pattern of the animals was recorded using a CCTV camera connected to the AnyMaze data equitation software (Stoelting Co., Wood Dale, IL, USA). The animals were introduced to the open field four times after the operation and prior to the treatments (at days 7, 14,17, and 21 post surgery) and then again after treatment as specified in Table 1. After each open field session, the following parameters of the animals' walking patterns were analyzed: total walking distance; percentages of time spent in each zone (see Figure 1); and the percentage of time that the animals spent walking with their operated side pointing against the wall.

\section{Assessment of spontaneous pain behavior using a CBS}

The solitary performance and social behavior for each animal was scored during a 10-minute observation period. Seven behavioral parameters were observed and recorded (three for solitary performance and four for social behavior). Table 2

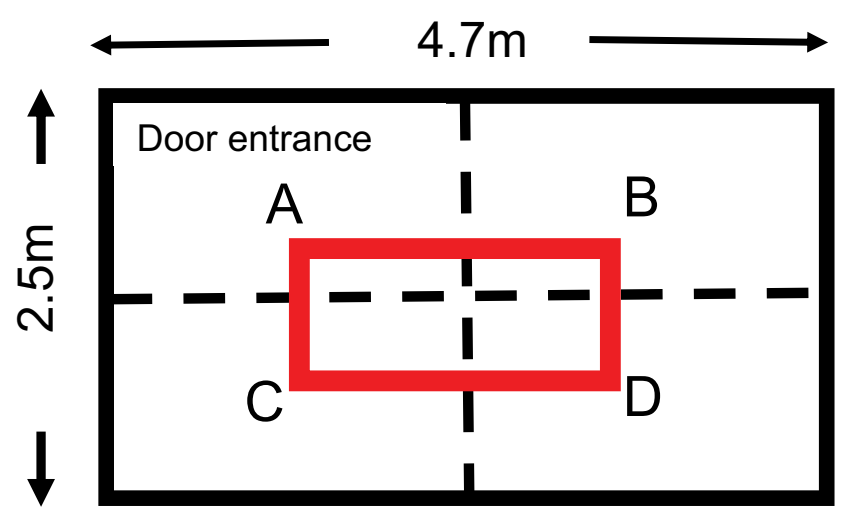

Figure I Open field dimensions and zones. Note: In red, the central zone. 
Table 2 Behavior parameters and scoring method

\begin{tabular}{|c|c|c|c|}
\hline Category & Parameter tested & Description of behavior & Score \\
\hline Solitary performance & Weight bearing & Equal on both legs & 0 \\
\hline \multirow[t]{6}{*}{ Max score: 4} & & Carrying weight mainly on intact leg & 1 \\
\hline & Appearance & Normal lying and walking & 0 \\
\hline & & Guarding the injured leg & I \\
\hline & Vocalization & Normal vocalization (low volume) & 0 \\
\hline & & High volume occasional cry & I \\
\hline & & Screaming and cries & 2 \\
\hline Social behavior & Restlessness & Normal behavior & 0 \\
\hline \multirow[t]{10}{*}{ Max score: 7} & & Pacing around the pen & I \\
\hline & & Jumping up and down and pacing around the pen & 2 \\
\hline & Agitation & Normal behavior & 0 \\
\hline & & Slightly moves away when approached & 1 \\
\hline & & Screaming and moves away when approached & 2 \\
\hline & Aggression & Friendly & 0 \\
\hline & & Moves away & I \\
\hline & & Attacking and biting his pen mates & 2 \\
\hline & Isolation & Normal behavior & 0 \\
\hline & & Moves away from pen mates & I \\
\hline
\end{tabular}

Notes: The scoring criteria used is based on a numerical rating scale (NRS) modified from Reyes et al. ${ }^{19}$ The behavior score was divided into two distinct categories: (I) solitary performance and (2) social behavior. The total score is the sum of all sub-scores.

summarizes the behavioral parameters and the corresponding scoring method. In general, the parameters relate to observing the animals' standing posture, including leg guarding and leg shaking, as well as their vocalization and social behavior (isolation and aggressiveness).${ }^{19}$ Some parameters were not as common and therefore carry more weight because they indicate more pain, for example, vocalization changes are less common than changes in weight bearing.

Each parameter was graded from 0 to 2 depending upon the observed behavior. The final score comprised the sum of all points from the seven parameters, that is, the higher the score, the more spontaneous pain behavior the animal expressed. The maximum possible score for an individual animal was 11 points. Spontaneous expression scores were recorded 1 day pre-surgery (Study Day -1), and 7, 14, 17, and 21 days post-surgery.

\section{Drugs}

Morphine (Teva Pharmaceutical Industries Ltd., Petah Tikva, Israel, Cat number: 111-29122280/A) was administered at doses of 1,2 , and $5 \mathrm{mg} / \mathrm{kg} \mathrm{IM}$, and gabapentin (USP Cat Number 1287303; USA) were administered at doses of $6 \mathrm{mg}$ / $\mathrm{kg}$ (IV). Buprenorphine was administered at a dose of $0.5 \mathrm{mg} /$ $\mathrm{kg}$ IM. The doses of morphine and gabapentin were chosen based on the active dose observed previously in this model. ${ }^{5}$

\section{Sample collection}

Six animals were dosed with morphine at doses of $1 \mathrm{mg} / \mathrm{kg}$ IM, buprenorphine at a dose of $0.5 \mathrm{mg} / \mathrm{kg} \mathrm{IM}$, or gabapentin at a dose of $6 \mathrm{mg} / \mathrm{kg} \mathrm{IV}$, respectively. The doses were selected based on a previous study suggesting activity of these drugs in von Frey, feather, and behavior score following PNT procedure in a swine model. ${ }^{5}$

\section{Cannulation of the animal for blood sampling}

Nine sham-operated animals were used for further PK study of morphine, buprenorphine, and gabapentin. One day prior to sample collection, the animals were anesthetized using a combination of ketamine $(10 \mathrm{mg} / \mathrm{kg}$ bodyweight $)$ and xylazine ( $2 \mathrm{mg} / \mathrm{kg}$ bodyweight) administered by the IM route. Following introduction of a venous catheter into the lateral ear vein, IV injection of diazepam (5-10 mg/animal) was administered. Anesthesia was maintained by isoflurane $1 \%-3 \%$ and oxygen $100 \%$ administered by an anesthetic machine via an endotracheal tube. The CVC was introduced into a central vein (e.g., cranial vena cava, external jugular, etc.) using a standard surgical (cut-down) technique. The $\mathrm{CVC}$ was fixed in place using sutures, and a dressing was applied to prevent dislodgment of the CVC by the animal. Blood samples were collected from the CVC into a syringe and the blood was transferred to EDTA-coated tubes.

Plasma separation was performed following centrifugation $(520 \times g$ which represents approximately $2,223 \mathrm{~g}$ for 10 minutes at room temperature). Following centrifugation, plasma was removed into pre-labeled plastic tubes that were snap frozen in dry ice or liquid nitrogen for further analysis. 
Blood drawing from animals treated with morphine and buprenorphine was performed at the following time points: pre-dosing, 30 minutes, $1,2,4,8,12$, and 24 hours post dosing.

For animals treated with gabapentin the time points were: pre-dosing, 10, 20, 30, and 40 minutes, and 1, 2, 4, 8, and 24 hours post dosing.

\section{Collection of CSF}

Animals were anesthetized by isoflurane $3 \%-5 \%$ in $100 \%$ $\mathrm{O}_{2}$ at a rate of $2-4 \mathrm{~L} / \mathrm{min}$, via face mask, positioned in lateral recumbence. The hair in the lumbar area was clipped with an electric clipper followed by surgical skin preparation (e.g., scrubbing the area with $4 \% \mathrm{w} / \mathrm{v}$ chlorhexidine gluconate and wiping with ethanol $70 \%$ ). The animals were flexed by bending the rear legs forward under the abdomen in order to separate the intervertebral spaces. An $18 \mathrm{G}$ spinal needle was inserted in the mid line between the palpable dorsal spinous processes located in the most cranial aspects of the bilateral tuber coxae (wings of ileum) which is the intervertebral space of L5-6 or L6-7. The needle was advanced slowly through the intervertebral space wherein the stylet was removed from the needle and clear CSF was collected to a pre-labeled tube.

CSF was collected at 1, 3, and 24 hours post drug administration in all groups.

\section{Bioanalytical methods}

Plasma or CSF samples were prepared as follows. Three volumes of acetonitrile containing internal standard were added to one volume of plasma or CSF to precipitate proteins. Samples were centrifuged at $3,000 \times g$ for 10 minutes and supernatant was removed for analysis by LC-MS/MS. Calibration standards and quality controls were made by preparation of a $1 \mathrm{mg} / \mathrm{mL}$ stock solution and subsequently a series of working solutions in methanol:water $(1: 1, \mathrm{v} / \mathrm{v})$, which were spiked into blank plasma to yield a series of calibration standard samples in the range of $1 \mathrm{ng} / \mathrm{mL}$ to $10 \mu \mathrm{g} /$ $\mathrm{mL}$ and quality control samples at three concentration levels (low, intermediate, and high). The resulting PK/pharmacodynamic plasma or CSF samples were treated identically to the calibration standards and quality control samples. LC-MS/ MS analysis was performed on a Phenomenex Kinetex C8 column $(4.6 \times 50 \mathrm{~mm}, 2.6 \mu \mathrm{m})($ Phenomenex, Torrance, CA, USA) with a linear gradient from mobile phase A ( $5 \%$ acetonitrile with $0.1 \%$ formic acid in water) to mobile phase B (100\% acetonitrile with $0.1 \%$ formic acid) at a flow rate of $1.0 \mathrm{~mL} / \mathrm{min}$ for 2.5 minutes using Shimadzu LC-20AD/ SIL-5000 LC system (Shimadzu Corp., Kyoto, Japan) and
AB/Sciex 4,000QTrap (Danaher Corporation, Washington, DC, USA). The MS quantification was carried out utilizing multiple reaction monitoring in the positive ion mode as follows: $\mathrm{m} / \mathrm{z}$ 468.4>55.1 for buprenorphine, $\mathrm{m} / \mathrm{z} 286.2>152.2$ for morphine, and m/z 172.1>154.1 for gabapentin.

\section{Results}

The current study was conducted to assess the spontaneous behavior of animals that underwent surgery for PNT-induced neuropathic pain. Two methods of assessment were used: computerized assessment of the open field test and assessment of spontaneous pain behavior using a CBS.

Animals introduced to the open field for the first time covered the entire area without any preference for any zone. This was the case whether the animals were introduced to the open field for 5 minutes or 30 minutes (Figure 2). The data show that following surgery (sham or PNT), repeated introduction of the pigs to the open field area did not affect the animal's behavior in the field. Measuring the total distance that the animals walked over a period of 5 minutes (Figure 3) showed similar results on trial 4 versus trial $1(76.6 \pm 10.2 \mathrm{~m}$ and $88.0 \pm 17.3 \mathrm{~m}$, respectively, no statistically significant difference). In addition, no difference was found between the
A

Trial 1 (5 minutes test)

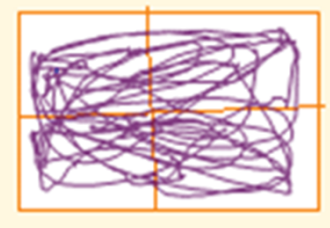

C

Trial 1 (30 minutes test)

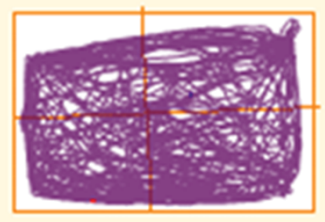

B

Trial 4 (5 minutes test)

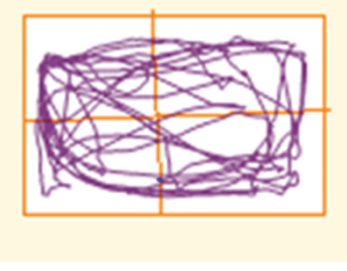

D

Trial 4 (30 minutes test)

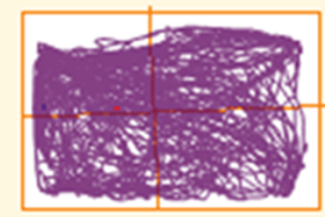

Figure 2 Walking pattern of a sham-operated animal in trials I and 4 on study days 0 and 21 , respectively.

Notes: (A) and (B) present a drawing of the walking pattern over a period of 5 minutes and $(\mathbf{C})$ and $(\mathbf{D})$ present a walking pattern over a period of 30 minutes. There is no difference in the animals' walking pattern even after introducing the animals to the open field four times. The animals walked in the entire open field area without any preference for a specific zone. 
Sham-operated animals $\quad \infty$ PNT animals

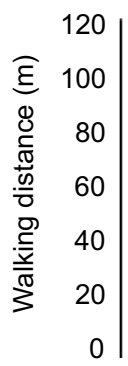

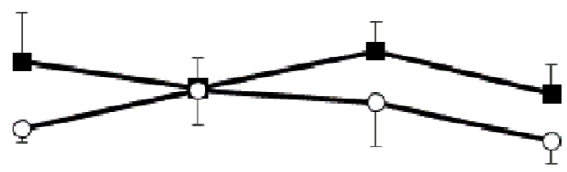

7

14

Study days

Figure 3 Walking distance in meters.

Notes: Full squares are sham-operated animals. Open circles are PNT-operated animals. No difference was found between the walking distances of the shamoperated animals versus the PNT-operated animals. Nor was there any difference between the walking distances between the testing days.

Abbreviation: PNT, peripheral neuritis trauma.
PNT animals and the sham-operated animals (trial 4 on study day 21: sham-operated animals, $76.6 \pm 10.2 \mathrm{~m}$ vs $59.6 \pm 7.8$ $\mathrm{m}$ for the PNT animals, no statistically significant difference). This finding is important because it suggests that even though the sciatic nerve was injured, the animals' ability to walk was preserved. However, although the total distance recorded was the same in the PNT animals and the sham-operated animals, the pattern of walking changed significantly following the PNT operation (Figure 4). PNT operated animals spent most of the time walking in the outer area of the open field and avoided entering the central area of the open field. This phenomenon was the same whether the animals spent 5 minutes or 30 minutes in the field and did not differ between trial 1 and 4 . When calculating the percentage of time that the animals spent in each zone (Table 3 ), the animals had no

5 minutes test

A

Trial 1

(Day 7 post PNT)

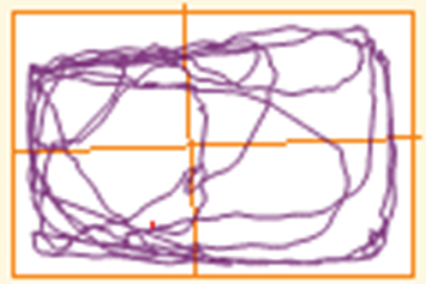

B

Trial 2

(Day 14 post PNT)

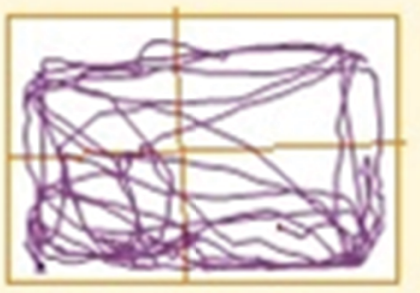

C

Trial 3

(Day 21 post PNT)

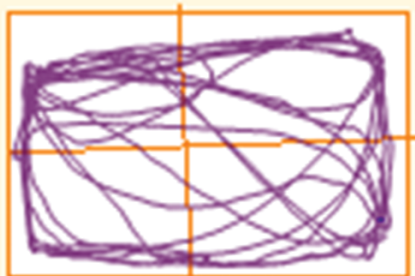

30 minutes test

D

Trial 1

(Day 7 post PNT)

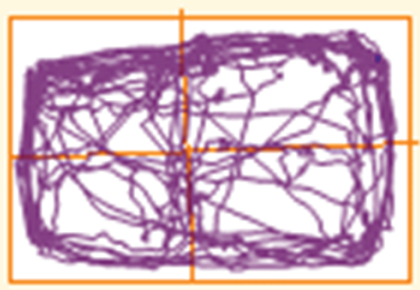

Trial 2

(Day 14 post PNT)

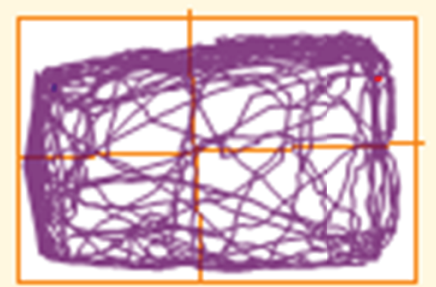

$\mathbf{F}$

Trial 3

(Day 21 post PNT)

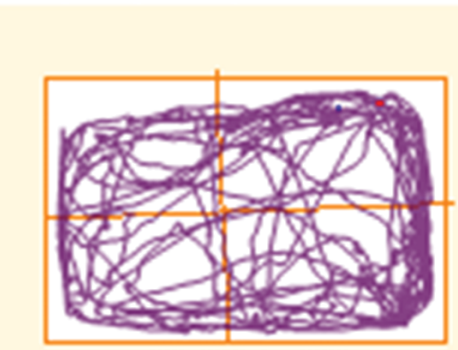

Figure 4 Changes in the walking pattern following PNT procedure.

Notes: $(\mathbf{A}),(\mathbf{B})$ and $(\mathbf{C})$ show the pattern from an animal that was monitored for a period of 5 minutes. (D), (E), and (F) show the pattern from an animal that was monitored for a period of 30 minutes. Animals tend to walk in the outer circle close to the walls of the open field pen. The same pattern was observed in the first trial (A and $\mathbf{D})$ and on the fourth trials (C and F), regardless of the amount of time that the animal spent in the open field (Trial 3, from day I7, is not shown).

Abbreviation: PNT, peripheral neuritis trauma. 
difficulty walking a distance (Zone $\mathrm{D}$, the zone furthest from the entrance zone vs Zone A, the entrance zone). However, the percentages of time that the animals spent in the central zone following PNT operation were reduced by more than $60 \%$ versus the sham-operated animals $(7.2 \% \pm 1.8 \%$ vs $18.5 \% \pm$ $3.55 \%$ for the 5 -minute test; $9.1 \% \pm 2.0 \%$ vs $32.7 \% \pm 5.3 \%$ for the 30-minute test; $P<0.05$ ). We examined whether the animals' walking pattern is related to guarding of the injured leg, that is, whether they spent more time walking with their injured leg protected by the walls of the open field. The PNT animals spend approximately two-third of the time walking with the operated leg pointed to the walls of the open-field suggesting a guarding behavior $(67.6 \% \pm 6.5 \%$ of the time spent in the open field.).

The next step was to evaluate the effect of drugs from different classes on the animals' performance in the open field. Morphine and buprenorphine, both opioids, and gabapentin, an anticonvulsant drug, were used. Morphine treatment resulted in a change in the walking pattern (Figure 5) as well as a dose-related increase in animals' walking distance (Figure 6). Animals treated with morphine walked mainly in Zone A, near the entrance to the open field and avoided walking in other zones (Figures 5 and 7). There was no significant difference in the time that the animals spent in the central zone following treatment with morphine versus pretreatment (Figure 8). Animals treated with buprenorphine at a dose of $0.5 \mathrm{mg} / \mathrm{kg}$ showed a similar change in the pattern of walking, that is, spent most of their time in Zone A. However, there was no significant change in the walking distance nor were there any changes in the animals' time spent in the central area versus pretreatment (Figure 8).

Treatment with gabapentin resulted in an alteration in the pattern of walking versus pretreatment in PNT-operated animals. The change in pattern was characterized by an increase in the time that the animals spent in the central area of the open field and equal presence in all zones (Figures 5,7 , and 8 ). No changes in the total walking distance were recorded (Figure 6).

Table 3 Walking pattern analysis

\begin{tabular}{|c|c|c|c|c|}
\hline \multirow[t]{3}{*}{ Parameters analyzed } & \multicolumn{4}{|c|}{ Time spent in the open field } \\
\hline & \multicolumn{2}{|l|}{5 minutes } & \multicolumn{2}{|l|}{30 minutes } \\
\hline & Sham & PNT & Sham & PNT \\
\hline Total distance walking (m) & $88.0 \pm 17.3$ & $64.3 \pm 5.6$ & $301.0 \pm 38.2$ & $213.4 \pm 25.0$ \\
\hline Percentage of time spent in the center area of the open field & $18.5 \pm 3.55$ & $7.2 \pm 1.8 *$ & $32.7 \pm 5.3$ & $9.1 \pm 2.0 *$ \\
\hline Percentage of time spent in Zone A & $27.2 \pm 2.1$ & $22.7 \pm 2.7$ & $24.4 \pm 5.6$ & $24.8 \pm 4.6$ \\
\hline Percentage of time spent in Zone B & $22.4 \pm 4.3$ & $24.6 \pm 3.1$ & $20.5 \pm 8.9$ & $26.5 \pm 2.1$ \\
\hline Percentage of time spent in Zone $\mathrm{C}$ & $24.8 \pm 3.0$ & $19.8 \pm 2.3$ & $33.3 \pm 12.8$ & $22.3 \pm 1.1$ \\
\hline Percentage of time spent in Zone D & $25.7 \pm 2.1$ & $32.2 \pm 4.0$ & $21.8 \pm 7.4$ & $26.4 \pm 4.4$ \\
\hline
\end{tabular}

Notes: Animals spent the same percentages of time in the zone close to the entrance (A) and the zone far from the entrance (Zone D) meaning that the animals were able to walk easily for a distance. See Figure I for description of Zones A to D. Following PNT operation, a statistically significant reduction was found in the time that the animals spent in the central zone regardless the time that the animals spent in the open field.

Note: $* P<0.05$ versus sham-operated animals.

Abbreviation: PNT, peripheral neuritis trauma.

A

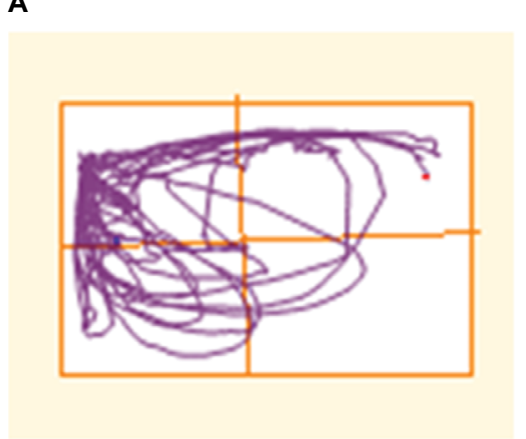

B

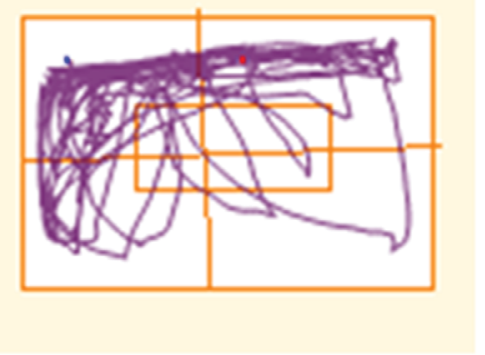

C

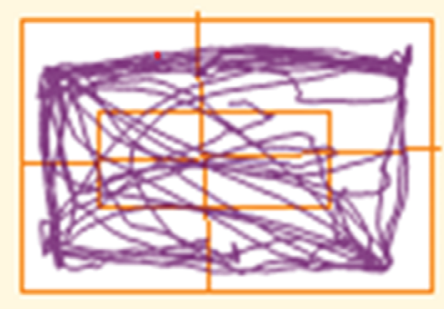

Figure 5 An example of the changes in walking pattern over a period of 5 minutes.

Notes: (A) PNT-operated animals treated with morphine at a dose of $2 \mathrm{mg} / \mathrm{kg} \mathrm{IM;} \mathrm{(B)} \mathrm{PNT-operated} \mathrm{animals} \mathrm{treated} \mathrm{with} \mathrm{buprenorphine} \mathrm{at} \mathrm{a} \mathrm{dose} \mathrm{of} 0.5 \mathrm{mg} / \mathrm{kg}$ IM; (C) PNT-operated animals treated with gabapentin $6 \mathrm{mg} / \mathrm{kg}$ IV. Animals treated with opioids (A and B) showed a clear specific pattern that was different than the pattern observed in animals treated with gabapentin.

Abbreviations: IM, intramuscular; IV, intravenous; PNT, peripheral neuritis trauma. 


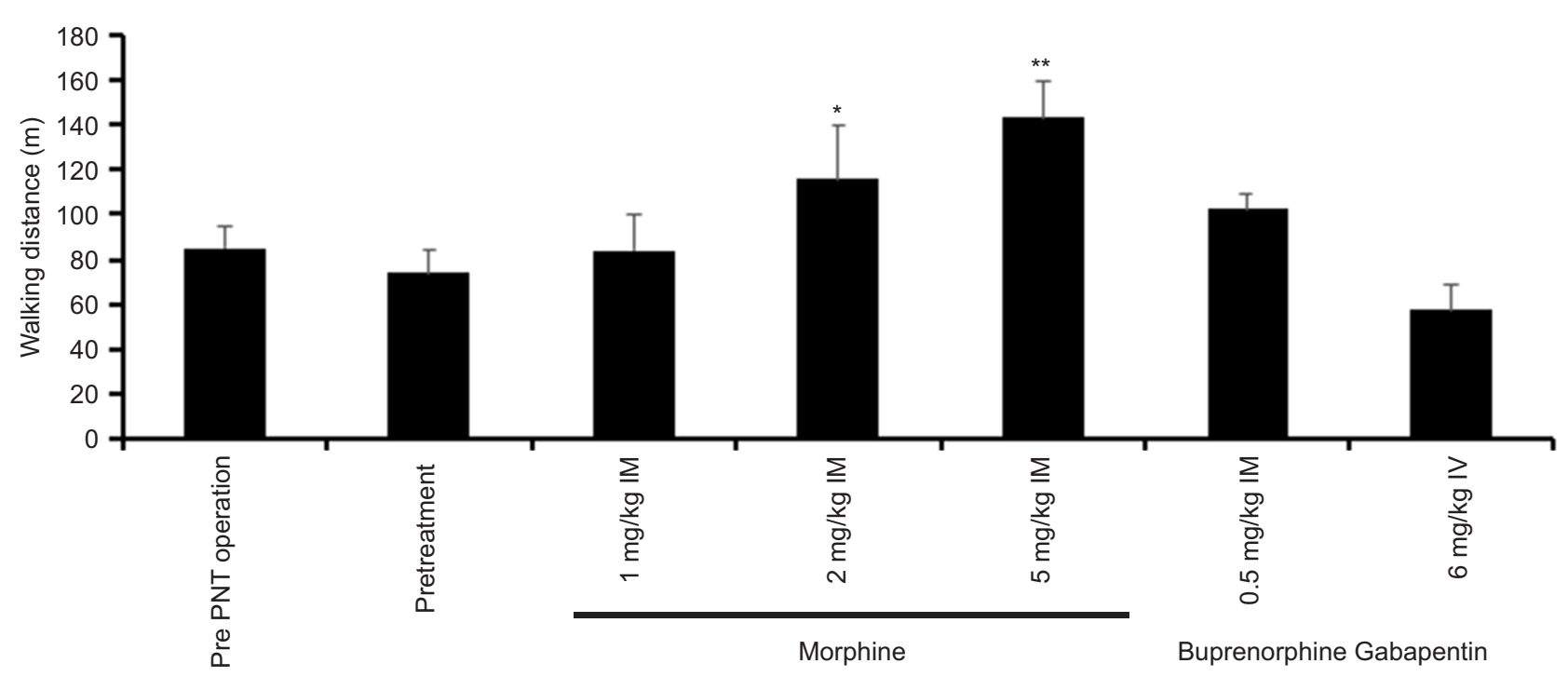

Figure 6 Mean group changes in total walking distance following treatment with either morphine, buprenorphine, or gabapentin in PNT-operated animals.

Notes: A significant increase in walking distance was detected only in animals treated with morphine. $* P<0.05$ versus pre-treatment; $* * P<0.01$ versus pre-treatment. Abbreviations: IM, intramuscular; IV, intravenous; PNT, peripheral neuritis trauma.

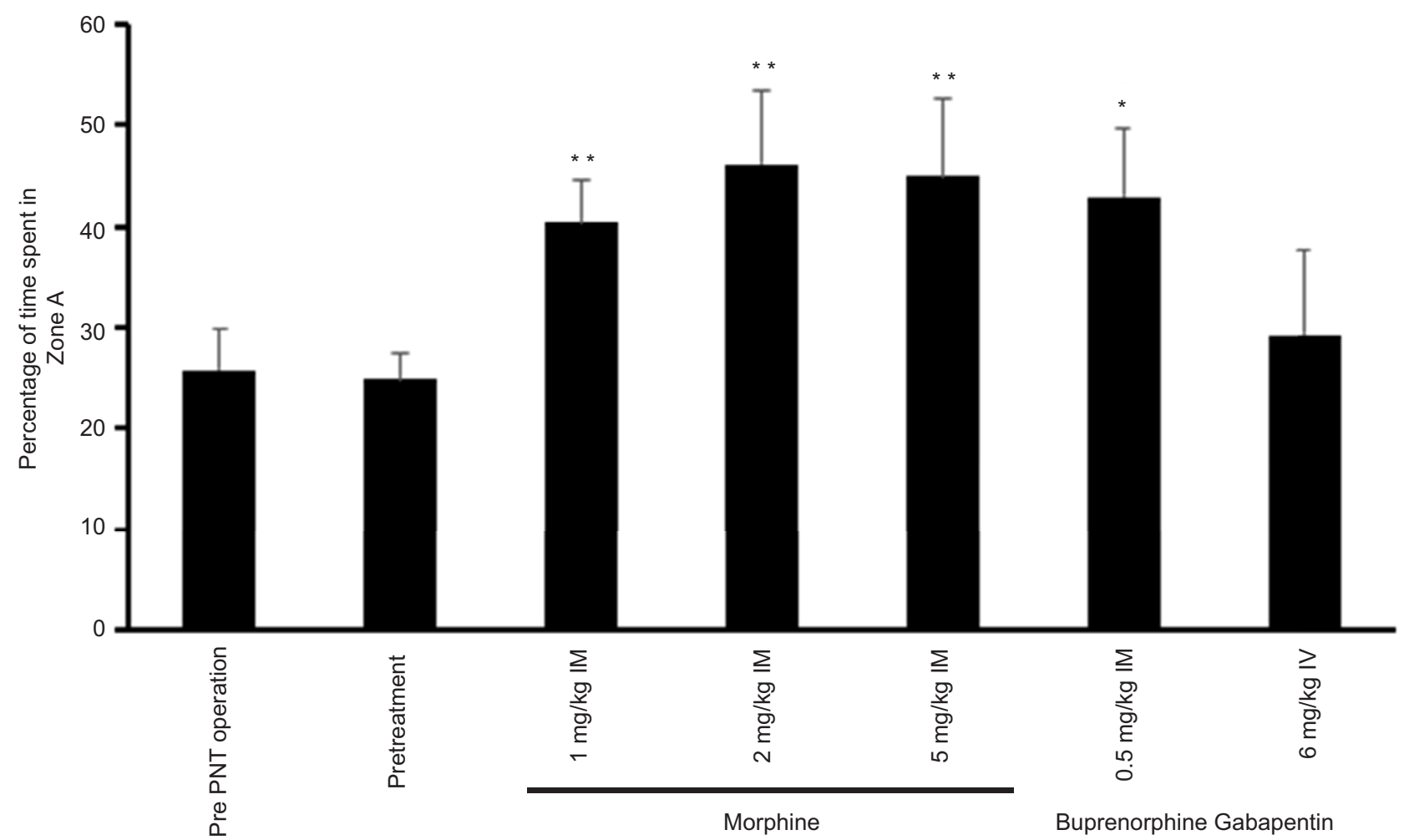

Figure 7 Mean group percentage of the time that the animals spent in Zone A (the entrance zone).

Notes: Animals treated with opioids spent significantly more time in Zone $A$ than prior to treatment or prior to operation. The time that the animals spent in Zone $A$ following gabapentin treatment did not differ from the time that the animals spent in Zone $A$ pretreatment or pre-operation. $* P<0.05$ versus pretreatment; $* * P<0.01$ versus pretreatment.

Abbreviations: IM, intramuscular; IV, intravenous; PNT, peripheral neuritis trauma.

Following treatment with either morphine, buprenorphine, or gabapentin, there were drug-specific alterations in the observational behavior score assessment in the PNToperated animals (Figure 9). Animals treated with morphine expressed significant improvement in weight bearing and in guarding their leg (appearance). However, treatment with morphine resulted in a dramatic increase in animals' aggressiveness and restlessness versus pretreatment (Figure 9). The 


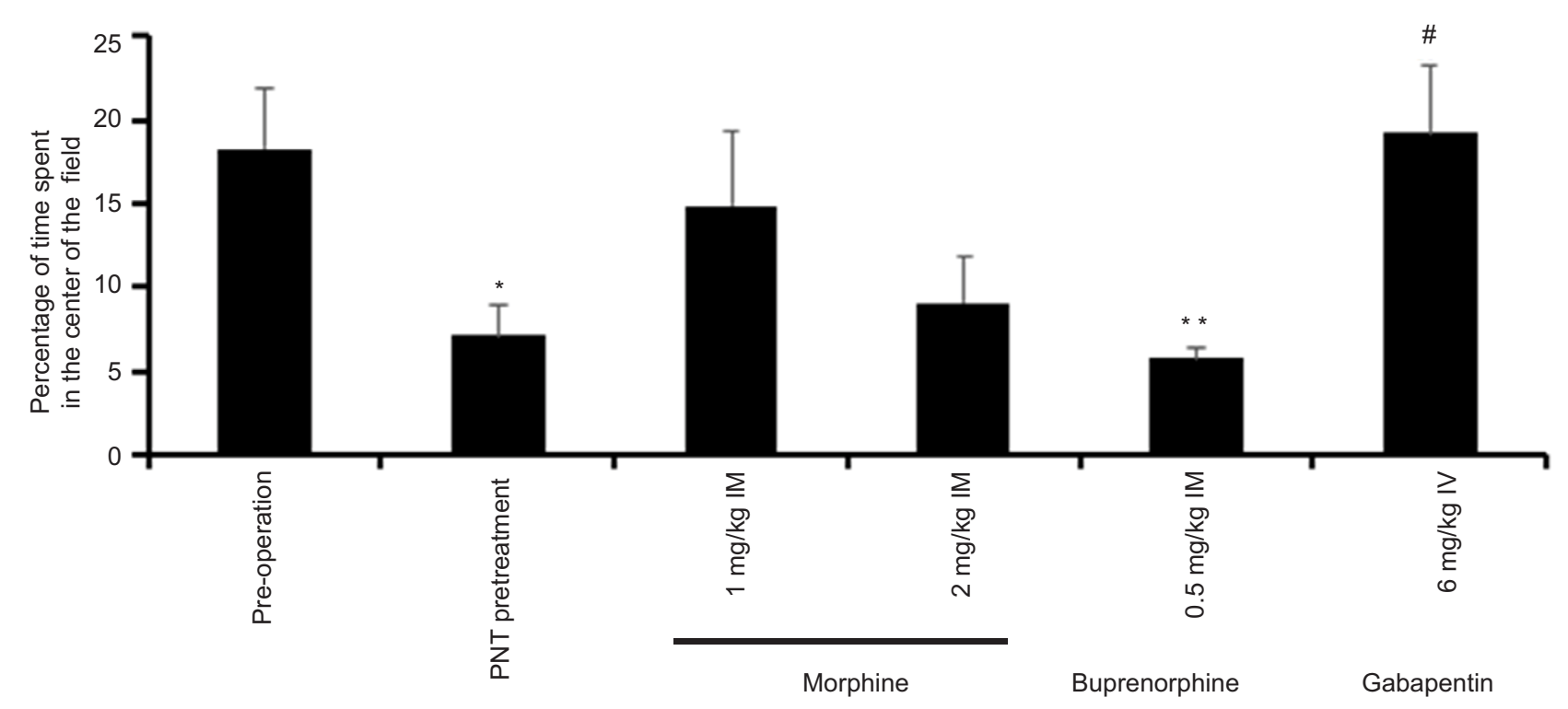

Figure 8 Mean group percentage of time that the animals spent in the central zone of the open field.

Notes: A significant reduction was observed following operation (PNT pre-dosing versus pre-operation). Treatment with gabapentin resulted in an increase in the percentage of time that animals spent in the central zone of the open field. $* P<0.05$ versus pre-operation; $* * P<0.01$ versus pre-operation; ${ }^{*} P<0.01$ versus $P N T$ pre-treatment. Abbreviations: IM, intramuscular; IV, intravenous; PNT, peripheral neuritis trauma.

Day 7

: Day 21

囚 Buprenorphine $0.5 \mathrm{mg} / \mathrm{kg} \mathrm{IM}$
Day 14

目Morphine $1 \mathrm{mg} / \mathrm{kg}$ IM

Vabapentin 6 mg/kg IV
Day 17

IIII Morphine 2 mg/kg IM

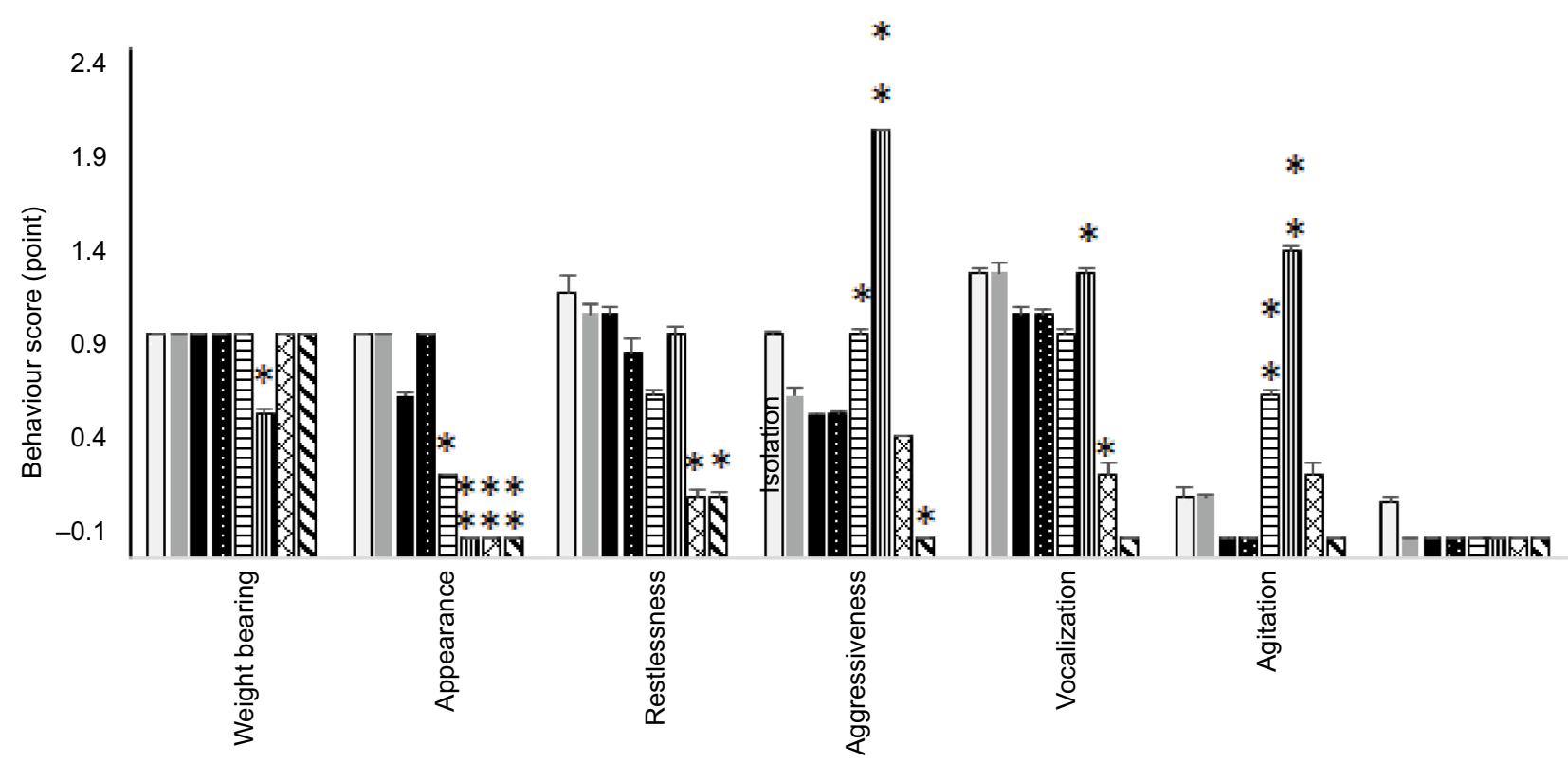

Figure 9 Changes in behavior score following treatment with morphine, buprenorphine, and gabapentin. Following treatment with morphine, animals' appearance and weight bearing was improved (reduced).

Notes: However, the animals expressed a dramatic increase in restlessness and aggressiveness. These phenomena were not observed following treatment with buprenorphine or gabapentin. $* P<0.05$ versus pretreatment on study day 21 ; $* * P<0.01$ versus pretreatment on study day 21 .

Abbreviations: IM, intramuscular; IV, intravenous; PNT, peripheral neuritis trauma. 
aggressiveness of animals treated with $5 \mathrm{mg} / \mathrm{kg}$ morphine became so severe that the animals ate the tails of their fellow pigs. Following treatment with buprenorphine, aggressiveness, and restless scores were not reduced on day 21 versus pretreatment; however, they were also not increased (Figure 9).

Treatment with gabapentin resulted in a reduction in all parameters of the behavior score, with the resulting score similar to the preoperative score, except for weight bearing, that is, animals did not carry weight equally on both sides following the treatment (Figure 9).

\section{PK results}

Following IM dosing of morphine at a dose of $1 \mathrm{mg} / \mathrm{kg} \mathrm{IM}$, the level of morphine was significantly reduced at 1-hour post-dosing (109 $\pm 35.2 \mathrm{mg} / \mathrm{mL})$ versus 0.5 hours (Tmax) post-dosing ( $348 \pm 86.6 \mathrm{mg} / \mathrm{mL})$ (Figure 10A). The plasma level of morphine at 24 hours was $16.3 \pm 8.62 \mathrm{ng} / \mathrm{mL}$. The level of morphine in the CSF was $79.0 \pm 40.4 \mathrm{ng} / \mathrm{mL}$ at 1 -hour post dosing and $41.3 \pm 20.3 \mathrm{ng} / \mathrm{mL}$ at 24 -hour post-dosing, suggesting that morphine clearance from the CSF in these pigs is relatively slow.

Following IM dosing of buprenorphine at a dose of 0.5 $\mathrm{mg} / \mathrm{kg}$, there was a reduction of more than $50 \%$ in the plasma concentration at 4 hours (from $46.6 \pm 5.5 \mathrm{mg} / \mathrm{mL}$ at 0.5 hours post dosing to $13.5 \pm 7.13 \mathrm{ng} / \mathrm{mL}$ at 4 hours post dosing; Figure 10B). The mean Tmax was calculated as 0.67 hours for plasma and 1.67 hours for CSF (Table 4). At 24 hours, a low level of buprenorphine was still detected in the plasma $(3.01 \pm 1.75 \mathrm{ng} / \mathrm{mL})$; no buprenorphine was detected in the spinal cord.

Following treatment with gabapentin at a dose of $5 \mathrm{mg}$ / $\mathrm{kg} \mathrm{IV}$, the drug level was reduced to less than half by 2 hours post-dosing $(1,470 \pm 295 \mathrm{ng} / \mathrm{mL}$ at 10 minutes post-dosing and $705 \pm 68 \mathrm{ng} / \mathrm{mL}$ at 2 hours post-dosing; Figure 10C). The calculated mean Tmax in the plasma was 1.67 hours and 3 hours for CSF. At 24 hours post-dosing, gabapentin was still detected in the plasma and CSF in two out of the three animals dosed.

\section{Discussion}

This study demonstrates quantitative changes in spontaneous behavior, as recorded during the open field test in pigs under neuropathic pain conditions. We also show that different drugs affect these changes in distinct ways, enabling the identification of a drug's class footprint. In our previous study, we evaluated the changes in spontaneous behavior using the traditional observation and scoring system. ${ }^{5}$ In the current study, we used the same scoring system, but in contrast to previous work, each category of the score was assessed separately and presented separately providing a valuable tool for identification of spontaneous changes in neuropathic pain in pigs and drug effect characterization. Together with the open field test, these tools enable, for the first time, the analysis of the spontaneous behavior changes and assessment of new therapeutics in pigs.

There are few reports on pigs' behavior in the open field test ${ }^{16,20}$ and even fewer reports about the locomotor activity of the swine following peripheral nerve injury and/or drug treatment. Belda et $\mathrm{al}^{17}$ studied the correlation between locomotion, histological findings, and lidocaine injection to the sciatic nerve. Their findings suggest that injection of lidocaine intraneurally did not alter motor function in piglets. Other studies refer to the changes in open field assessment following treatment with CNS acting drugs such as cocaine ${ }^{15}$ or meloxicam. ${ }^{21}$ In one study, following abdominal surgery, pigs exhibited reduction in functions such as eating, drinking, and standing. Treatment with epidural morphine and transdermal fentanyl showed a beneficial effect on the reduced activity, with good correlation with better weight gain and lower levels of cortisol. ${ }^{22}$ However, the authors of this study did not report any changes in locomotor activity. Our study used a computerized system to characterize pig locomotor activity following PNT operation and subsequent treatment with different drug classes. Our findings show the following:

1. There is no alteration in animals' behavior in four repeated open field trials.

2. The animals' behavior in the open field is not affected by the time that the animals spend in the field, up to 30 minutes.

3. PNT operation did not lead to changes in animals' walking distance, suggesting minimal interference with motor function.

4. PNT operation resulted in a significant change in the animals' walking pattern. Following the operation, the animals tend to walk next to the open space walls, avoiding entering the central zone.

5. Treatment with buprenorphine, morphine, or gabapentin altered the animals walking patterns in a drug-specific manner.

6. The PK profile of buprenorphine, morphine, and gabapentin shows that gabapentin exhibited the slowest clearance and the highest Tmax, suggesting prolonged exposure. 

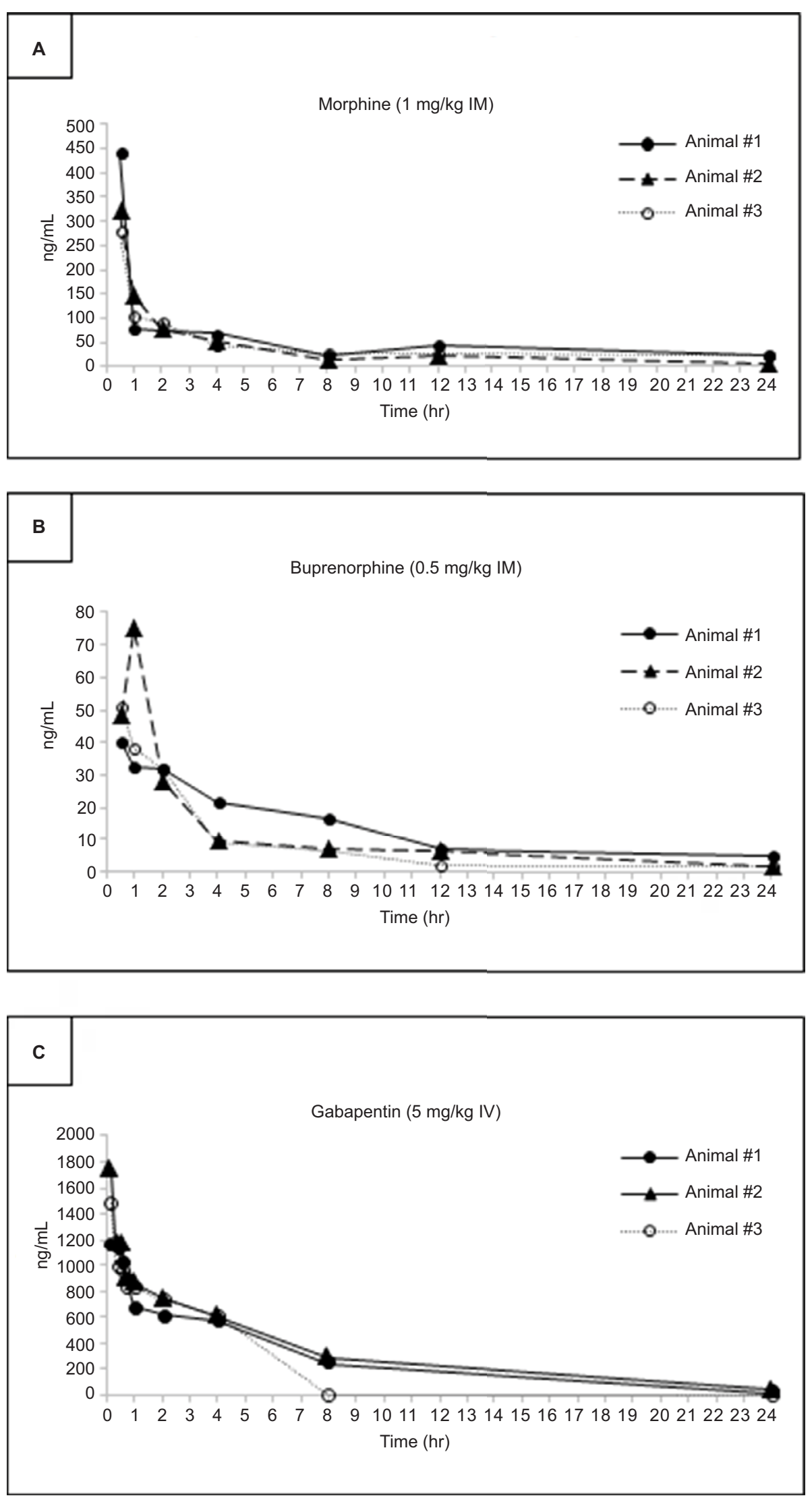

Figure 10 Plasma concentration of morphine (A), buprenorphine (B), and gabapentin (C).

Abbreviations: IM, intramuscular; IV, intravenous. 
Table 4 PK data

\begin{tabular}{|c|c|c|c|c|c|c|c|c|}
\hline \multicolumn{9}{|l|}{ Plasma } \\
\hline \multicolumn{3}{|c|}{ Buprenorphine $0.5 \mathrm{mg} / \mathrm{kg}$ IM } & \multicolumn{3}{|c|}{ Morphine I mg/kg IM } & \multicolumn{3}{|c|}{ Gabapentin 5 mg/kg IV } \\
\hline Animal \# & $\mathbf{T}_{\max }(\mathrm{hr})$ & $C_{\max }(n g / m L)$ & Animal \# & $\mathbf{T}_{\max }(\mathbf{h r})$ & $C_{\max }(n g / m L)$ & Animal \# & $T_{\text {max }}(h r)$ & $C_{\max }(\mathrm{ng} / \mathrm{mL})$ \\
\hline I & 0.50 & 40.4 & I & 0.50 & 445 & I & 0.167 & $\mathrm{I}, \mathrm{I} 70$ \\
\hline 2 & 1.00 & 75.2 & 2 & 0.50 & 319 & 2 & 0.167 & 1,760 \\
\hline 3 & 0.50 & 50.8 & 3 & 0.50 & 279 & 3 & 0.167 & $\mathrm{I}, 480$ \\
\hline Mean & 0.67 & 55.5 & Mean & 0.50 & 348 & Mean & 0.167 & 1,470 \\
\hline SD & 0.29 & 17.9 & SD & 0.00 & 86.6 & SD & 0.00 & 295 \\
\hline Percentage of CV & 43.3 & 32.2 & Percentage of CV & 0.0 & 24.9 & Percentage of CV & 0.00 & 20.1 \\
\hline \multicolumn{9}{|l|}{ CSF } \\
\hline \multicolumn{3}{|c|}{ Buprenorphine $0.5 \mathrm{mg} / \mathrm{kg}$ IM } & \multicolumn{3}{|c|}{ Morphine I mg/kg IM } & \multicolumn{3}{|c|}{ Gabapentin 5 mg/kg IV } \\
\hline Animal \# & $T_{\text {max }}(h r)$ & $C_{\max }(n g / m L)$ & Animal \# & $\mathbf{T}_{\max }(\mathbf{h r})$ & $C_{\max }(n g / m L)$ & Animal \# & $\mathbf{T}_{\max }(\mathbf{h r})$ & $C_{\max }(\mathrm{ng} / \mathrm{mL})$ \\
\hline $\mathrm{I}$ & 1.00 & 1.04 & 1 & 3.00 & 91.7 & 1 & 3.00 & 567 \\
\hline 2 & 3.00 & 0.506 & 2 & 1.00 & 62.1 & 2 & 3.00 & 459 \\
\hline 3 & 1.00 & 1.37 & 3 & 1.00 & 125 & 3 & 3.00 & 307 \\
\hline Mean $(n=3)$ & 1.67 & 0.972 & Mean & 1.67 & 92.9 & Mean & 3.00 & 444 \\
\hline SD & 1.15 & 0.436 & SD & 1.15 & 31.5 & SD & 0.00 & $|3|$ \\
\hline Percentage of CV & 69.3 & 44.9 & Percentage of CV & 69.3 & 33.9 & Percentage of CV & 0.00 & 29.4 \\
\hline
\end{tabular}

Abbreviations: $\mathrm{C}_{\max }$, maximum concentration detected; CSF, cerebrospinal fluid; CV, central vein; IM, intramuscular; IV, intravenous; PK, pharmacokinetic; $\mathrm{T}_{\text {max }}$, time of which the maximum concentration of the drug was detected.

These data are in accordance with a study exploring the effect of apomorphine on pigs that shows that the animals walked the same distance during a period of 10 minutes blocks within 1 hour. Namely, the animals walked the same distance during the first 10 minutes of the hour (minute 1-10) and the last 10 minutes of the hour (minutes 50-60). The researchers also showed that the animals had no zone preference. ${ }^{23}$ Following treatment with apomorphine, the authors demonstrated a significant alteration in the animals' walking distance versus non-treated animals. Other studies have also shown the effect of ketamine or diazepam on locomotor activity. ${ }^{16}$ None of these studies referred to the pattern of walking or to changes in the pattern under pain conditions.

Following painful manipulation, behavior scores of animals are commonly assessed in rodents and in large animals in veterinarian medicine. A comprehensive review of pain assessment summarizes functional changes in pigs following elective manipulations such as castration or teeth cutting or diseases that are typical to pigs. ${ }^{24}$ The authors use escape behavior, posture changes, avoidance response to stimuli, and vocalization as the main categories for assessing changes following painful manipulations.

The behavior categories in our study include these indicators and additional ones such as aggressiveness or isolation behavior. In a previous study, this detailed score was used to assess the effect of PNT injury in pigs. ${ }^{5}$ The study showed that following PNT, there were alterations in almost all indicators and that treatment with gabapentin or morphine was beneficial in a dose-related manner. In our study, the same scoring method was used but instead of using a composite score of the different indicators, each indicator was assessed and presented separately. This analysis suggests that different analgesics affect the score differently. For example, 2 hours following gabapentin treatment, the animals remain calm with improved posture (weight bearing), reduced vocalization, and reduced escape behavior (agitation). This is in line with the PK results suggesting an accumulation of gabapentin in the spinal cord and a Tmax of 3 hours following IV administration. Clinical studies with gabapentin have shown a CSF Tmax of 3-5 hours postoral administration of gabapentin. ${ }^{25}$ Furthermore, after treatment with gabapentin, the animals entered the central area of the open field suggesting a reduction in anxiety-related behavior. Studies in humans have shown that preoperative treatment with gabapentin resulted in a reduction in cortisol levels, an acceptable stress-related marker. These changes correlated well with the reduction in the visual analog scale score for pain. ${ }^{26}$ Pregabalin has been shown to reduce anxiety in patients suffering from poststroke pain. ${ }^{27}$ Other clinical studies showed that treatment with gabapentin significantly improved motor function following spinal cord injury ${ }^{28}$ and reduced dystonia severity in children. However, its effect on locomotor function following pain induction in rodents is not clear. ${ }^{29-32}$ 
When treated with morphine, the pigs expressed a doserelated increase in agitation, aggressiveness, and restless behavior, together with an improvement in posture and appearance. The effect of morphine on the animals' restless behavior was also noted in the open field, expressed as a doserelated increase in walking distance and a significant change in the walking pattern. Morphine has long been used in the treatment of pigs. A study by Risdahl et al, $1992^{33}$ shows that following treatment with morphine at doses ranging from $1.5 \mathrm{mg} / \mathrm{kg}$ to $10 \mathrm{mg} / \mathrm{kg}$, full analgesia was noted up to $4-6$ hours post dosing. The authors also stated that the excitatory effect of morphine was expressed as an increase in movement, hyperthermia, and an increase in respiratory rate; they showed that this increase is both drug and dose dependent. Use of epidural morphine following abdominal surgery showed an analgesic effect without any excitation behavior or aggression mentioned. ${ }^{22}$ The current study also shows an increase in the walking distance in the open field and a clear pattern change that might be related to stereotypic behavior. The PK analysis suggests that the repetitive and aggressive behaviors are in line with plasma Tmax, which occurred at 0.5 hours post dosing. The Tmax in the CSF occurred at 1.67 hours. These data are in accordance with those of other studies showing a rapid accumulation of morphine in the CSF following IV dosing ${ }^{22}$ and a relatively slow clearance following epidural dosing. ${ }^{34}$

Very little is known about stereotypic behavior in pigs and the relationship between this behavior and morphine. ${ }^{35} \mathrm{~A}$ study that assessed the level of opioid receptors in the brain and stereotypic behavior in sows found a significant role of $\mathrm{K}$-opioid receptors in the frontal cortex and a correlation between the mu opioid receptors and discomfort. ${ }^{36}$ However, a different study suggests that that the opioid system might not be the sole system involved in this behavior. ${ }^{23}$

The data obtained from the open field test in the current study show a stereotypic behavior related to morphine dosing. The behavior was characterized by repetitive walking back and forth, focusing mainly in Zone A of the open field (the entrance zone). This was accompanied by a doserelated increase in the distance of walking. The animals also expressed a dose-related increase in aggressive behavior expressed as chewing each other's tails. Hyperactivity following morphine dosing is reported in rodents, when an injection of $20 \mathrm{mg} / \mathrm{kg}$ to mice resulted in stereotypic behavior with hyperactivity and reduced exploration behavior. ${ }^{37}$ However, studies in mice suggest that morphine has an anti-aggressive behavior effect. ${ }^{38}$
Interestingly, animals dosed with buprenorphine, a partial mu opioid receptor agonist with high affinity and slow dissociation from mu opioid receptors, also expressed preference for zone A, although without stereotypic behavior and with a decrease in the aggressiveness score. Also, there was no change in the percentage of time that the animals spent in the central zone versus PNT-operated saline-treated animals. Other studies have shown improvement in locomotor activity in weaned lamed pigs following treatment with buprenorphine. ${ }^{39}$

The plasma Tmax for buprenorphine was between 0.5 and 1 hours (mean of $0.67 \pm 0.29$ hour), suggesting a rapid effect. This is in accordance with other studies in minipigs showing the plasma concentration of buprenorphine following IV, slow-release subcutaneous dosing, and transdermal dosing. ${ }^{40}$

Finally, the cost aspect of swine models must also be considered. Preclinical animal studies provide important information regarding efficacy, toxicology and mode of action, inferring the therapeutic activity in humans. Swine models provide the bridge between early rodent studies and human clinical ones, serving as an important de-risking tool for the prediction of success or failure in human studies. Additionally, swine models have gained importance as an alternate species for toxicology studies traditionally performed in NHPs and canines. ${ }^{41,42}$ Providing both efficacy and safety studies in pigs as a relevant translationally predictive model for humans may serve to reduce costs by early identification of any safety, efficacy or absorption issues. Costs expended on pig studies, while higher than for rodent studies, may ultimately serve to actually reduce overall program costs by identifying issues and potential failures much earlier.

In conclusion, the current study shows locomotor pattern changes following PNT surgery using the open field test for the first time. In addition, this study suggests that the open field assay can serve as a tool to detect the effect of new pain therapeutics on spontaneous changes in behavior of the pigs using a computerized non-biased method.

\section{Abbreviation list}

CBS, composite behavior scale

CCTV, close circuit television

CFA, complete Freund's adjuvant

Cmax, maximum concentration detected

CNS, central nervous system

CSF, cerebrospinal fluid

CVC, central vein cannula

IASP, international Association for the Study of Pain 
IM, intramuscular

IV, intravenous

LC, liquid chromatography

MS, mass spectrometry

NHP, non-human primates

PK, pharmacokinetic

PNT, peripheral neuritis trauma

Tmax, time of which the maximum concentration of the drug was detected

\section{Disclosure}

The authors report no conflicts of interest in this work.

\section{References}

1. Philips BH, Weisshaar CL, Winkelstein BA. Use of the rat grimace scale to evaluate neuropathic pain in a model of cervical radiculopathy. Comp Med. 2017;67(1):34-42.

2. Cho H, Jang Y, Lee B, et al. Voluntary movements as a possible nonreflexive pain assay. Mol Pain. 2013;9:25.

3. Mogil JS, Davis KD, Derbyshire SW. The necessity of animal models in pain research. Pain. 2010;151(1):12-17.

4. Gregory NS, Harris AL, Robinson CR, Dougherty PM, Fuchs PN, Sluka KA. An overview of animal models of pain: disease models and outcome measures. J Pain. 2013;14(11):1255-1269.

5. Castel D, Sabbag I, Brenner O, Meilin S. Peripheral neuritis trauma in pigs: a neuropathic pain model. J Pain. 2016;17(1):36-49.

6. Castel D, Willentz E, Doron O, Brenner O, Meilin S. Characterization of a porcine model of post-operative pain. Eur J Pain. 2014;18(4): 496-505.

7. Castel D, Sabbag I, Meilin S. The effect of local/topical analgesics on incisional pain in a pig model. J Pain Res. 2017;10:2169-2175.

8. Mogil JS. Animal models of pain: progress and challenges. Nat Rev Neurosci. 2009;10(4):283-294.

9. Joshi SK, Honore P. Animal models of pain for drug discovery. Expert Opin Drug Discov. 2006;1(4)323-334.

10. Blackburn-Munro G. Pain-like behaviours in animals - how human are they? Trends Pharmacol Sci. 2004;25(6):299-305.

11. Swindle MM, Makin A, Herron AJ, Clubb FJ, Frazier KS. Swine as models in biomedical research and toxicology testing. Vet Pathol. 2012;49(2):344-356.

12. van der Staay FJ, Pouzet B, Mahieu M, Nordquist RE, Schuurman T. The d-amphetamine-treated Göttingen miniature pig: an animal model for assessing behavioral effects of antipsychotics. Psychopharmacology (Berl). 2009;206(4):715-729.

13. Ennaceur A, Chazot PL. Preclinical animal anxiety research - flaws and prejudices. Pharmacol Res Perspect. 2016;4(2):e00223.

14. Seibenhener ML, Wooten MC. Use of the Open Field Maze to measure locomotor and anxiety-like behavior in mice. J Vis Exp. 2015; (96):e52434.

15. Laferrière A, Ertug F, Moss IR. Prenatal cocaine alters openfield behavior in young swine. Neurotoxicol Teratol. 1995;17(2): 81-87.

16. Zhong M, Shoemake C, Fuller A, et al. Development of a Functional Observational Battery in the Minipig for Regulatory Neurotoxicity Assessments. Int J Toxicol. 2017;36(2):113-123.

17. Belda E, Laredo FG, Gil F, et al. Ultrasound-guided administration of lidocaine into the sciatic nerve in a porcine model: correlation between the ultrasonographic evolution of the lesions, locomotor function and histological findings. Vet J. 2014;200(1):170-174.

18. Zimmermann M. Ethical considerations in relation to pain in animal experimentation. Acta Physiol Scand Suppl. 1986;554:221-233.
19. Reyes L, Tinworth KD, Li KM, Yau DF, Waters KA. Observer-blinded comparison of two nonopioid analgesics for postoperative pain in piglets. Pharmacol Biochem Behav. 2002;73(3):521-528.

20. Henze DA, Urban MO. Large animal models for pain therapeutic development Translational pain research: from mouse to man. In: Kruger L, Light AR, editors. Frontiers in Neuroscience. Boca Raton (FL): CRC Press/Taylor \& Francis; 2010.

21. Friton GM, Philipp H, Schneider T, Kleemann R. Investigation on the clinical efficacy and safety of meloxicam (Metacam) in the treatment of non-infectious locomotor disorders in pigs. Berl Munch Tierarztl Wochenschr. 2003;116(9-10):421-426.

22. Malavasi LM, Nyman G, Augustsson H, Jacobson M, Jensen-Waern M. Effects of epidural morphine and transdermal fentanyl analgesia on physiology and behaviour after abdominal surgery in pigs. Lab Anim. 2006;40(1):16-27.

23. Lind NM, Vinther M, Hemmingsen RP, Hansen AK. Validation of a digital video tracking system for recording pig locomotor behaviour. $J$ Neurosci Methods. 2005;143(2):123-132.

24. Ison SH, Clutton RE, di Giminiani P, Rutherford KM. A Review of Pain Assessment in Pigs. Front Vet Sci. 2016;3:108.

25. Ben-Menachem E, Söderfelt B, Hamberger A, Hedner T, Persson LI. Seizure frequency and CSF parameters in a double-blind placebo controlled trial of gabapentin in patients with intractable complex partial seizures. Epilepsy Res. 1995;21(3):231-236.

26. Karbić VO, Škoda M, Antončić D, Krištofić I, Komar D, Trobonjača $Z$. Gabapentin-induced changes of plasma cortisol level and immune status in hysterectomized women. Int Immunopharmacol. 2014;23(2):530-536.

27. Kim JS, Bashford G, Murphy TK, Martin A, Dror V, Cheung R. Safety and efficacy of pregabalin in patients with central post-stroke pain. Pain. 2011;152(5):1018-1023.

28. Cragg JJ, Haefeli J, Jutzeler CR, et al. Effects of Pain and Pain Management on Motor Recovery of Spinal Cord-Injured Patients: a Longitudinal Study. Neurorehabil Neural Repair. 2016;30(8):753-761.

29. Zimcikova E, Simko J, Karesova I, Kremlacek J, Malakova J. Behavioral effects of antiepileptic drugs in rats: are the effects on mood and behavior detectable in open-field test? Seizure. 2017;52:35-40.

30. Câmara CC, Ramos HF, da Silva AP, et al. Oral gabapentin treatment accentuates nerve and peripheral inflammatory responses following experimental nerve constriction in Wistar rats. Neurosci Lett. 2013;556:93-98.

31. Zhang WS, Xu H, Xu B, Sun S, Deng XM, Zhang YQ. Antihyperalgesic effect of systemic dexmedetomidine and gabapentin in a rat model of monoarthritis. Brain Res. 2009;1264:57-66.

32. Wallace VC, Segerdahl AR, Blackbeard J, Pheby T, Rice AS. Anxietylike behaviour is attenuated by gabapentin, morphine and diazepam in a rodent model of HIV anti-retroviral-associated neuropathic pain. Neurosci Lett. 2008;448(1-9):153-156.

33. Risdahl JM, Chao C, Murtaugh MP, Peterson PK, Molitor TW. Acute and chronic morphine administration in swine. Pharmacol Biochem Behav. 1992;43(3):799-806.

34. Bernards CM, Shen DD, Sterling ES, et al. Epidural, cerebrospinal fluid, and plasma pharmacokinetics of epidural opioids (part 1): differences among opioids. Anesthesiology. 2003;99(2):455-465.

35. von Borell E, Hurnik JF. Stereotypic behavior, adrenocortical function, and open field behavior of individually confined gestating sows. Physiol Behav. 1991;49(4):709-713.

36. Zanella AJ, Broom DM, Hunter JC, Mendl MT. Brain opioid receptors in relation to stereotypies, inactivity, and housing in sows. Physiol Behav. 1996;59(4-5):769-775.

37. Hodgson SR, Hofford RS, Buckman SG, Wellman PJ, Eitan S. Morphineinduced stereotyped thigmotaxis could appear as enhanced fear and anxiety in some behavioural tests. J Psychopharmacol. 2010;24(6):875-880.

38. Rodríguez-Arias M, Miñarro J, Simón VM. Development of tolerance to the antiaggressive effects of morphine. Behav Pharmacol. 2001;12(3):221-224. 
39. Meijer E, van Nes A, Back W, van der Staay FJ. Clinical effects of buprenorphine on open field behaviour and gait symmetry in healthy and lame weaned piglets. Vet J. 2015;206(3):298-303.

40. Thiede AJ, Garcia KD, Stolarik DF, Ma J, Jenkins GJ, Nunamaker EA. Pharmacokinetics of sustained-release and transdermal buprenorphine in Göttingen minipigs (Sus scrofa domestica). J Am Assoc Lab Anim Sci. 2014;53(6):692-699.
41. Rubic-Schneider T, Christen B, Brees D, Kammüller M. Minipigs in Translational Immunosafety Sciences. Toxicol Pathol. 2016;44(3):315-324.

42. Bode G, Clausing P, Gervais F, et al; Steering Group of the RETHINK Project. The utility of the minipig as an animal model in regulatory toxicology. J Pharmacol Toxicol Methods. 2010;62(3):196-220.

\section{Publish your work in this journal}

The Journal of Pain Research is an international, peer reviewed, open access, online journal that welcomes laboratory and clinical findings in the fields of pain research and the prevention and management of pain. Original research, reviews, symposium reports, hypothesis formation and commentaries are all considered for publication.

\section{Dovepress}

The manuscript management system is completely online and includes a very quick and fair peer-review system, which is all easy to use. Visit http://www.dovepress.com/testimonials.php to read real quotes from published authors. 